\title{
Properties of modified natural surfactant after exposure to fibrinogen in vitro and in an animal model of respiratory distress syndrome
}

\author{
Andrea Calkovska ${ }^{1,2}$, Bim Linderholm ${ }^{1}$, Marie Haegerstrand-Björkman ${ }^{1}$ and Tore Curstedt ${ }^{1}$
}

BACKGROUND: Plasma proteins are known to interfere with pulmonary surfactant. Studies have proven the hypothesis that fibrinogen preserves exogenous surfactant subjected to longterm surface area cycling.

METHODS: The exogenous surfactant Curosurf was subjected to long-term surface area cycling without or with fibrinogen (ratio 2:1 w/w) and was tested by captive bubble surfactometer and on newborn premature rabbits.

RESULTS: Surface tension increased in Curosurf $(80 \mathrm{mg} / \mathrm{ml})$ samples without fibrinogen after 6-12 d of cycling. In samples with fibrinogen the cycling time had no effect on surface tension. Addition of fibrinogen to surfactant prevented lipid peroxidation. Lung gas volumes of animals with noncycled Curosurf or Curosurf cycled with fibrinogen for $6 \mathrm{~d}$ were comparable and higher than in rabbits with Curosurf cycled without fibrinogen. Alveolar volume density was higher in groups with noncycled Curosurf or Curosurf cycled with fibrinogen than in Curosurf cycled without fibrinogen (both $P<0.001$ ).

CONCLUSION: The effect of fibrinogen on pulmonary surfactant cycled at $37^{\circ} \mathrm{C}$ depends both on surfactant concentration and cycling time. At high phospholipid concentration used in clinical practice fibrinogen has a protective effect on biophysical and physiological properties of natural modified surfactant subjected to surface area cycling. This effect is partially mediated by reduction in lipid peroxidation.

A lveolar protein leakage due to increased permeability of alveolar-capillary membrane is one of the key events in acute respiratory distress syndrome. Numerous in vitro and in vivo studies have demonstrated surfactant-inhibiting properties of plasma proteins, with fibrinogen and fibrin monomer being the strongest inhibitors (1-3). This protein-induced surfactant inactivation may be abolished at sufficiently high surfactant phospholipid concentrations (4).

In contrast, a recent in vitro study under conditions resembling the exposure of surfactant to inhibitors in the lungs revealed that neither serum albumin nor fibrinogen were persistently inhibitory to pulmonary surfactant and normal near-zero minimum surface tension values were obtained after a small number of cycles (5). Moreover, there is evidence of protective effects of plasma proteins on surfactant inactivation. For example, simultaneous exposure of lung surfactant to serum proteins and reactive oxygen species prevented, rather than promoted, free-radical modifications of surfactant lipids and proteins (6). Surface area cycling of beractant (Survanta, Abbott Nutrition, Columbus, $\mathrm{OH}$ ) and $\mathrm{KL}_{4}$ surfactant mixed with fibrinogen showed the formation of heavy/ultra-heavy subtypes instead of less active light subtypes (7).

Surface area cycling is an in vitro method intended to reproduce the cyclic expansion and compression of the alveolar surface during respiratory cycles. In this procedure, a tube containing a surfactant suspension is rotated end over end at $37^{\circ} \mathrm{C}$ so that the surface area of the suspension changes twice each cycle. The method was originally developed by Gross and Narine (8) to study conversion of large functionally superior surfactant aggregates (LAs) into small functionally inferior surfactant aggregates (SAs). In vitro cycling in the presence of supernatant from bronchoalveolar lavage fluid of injured animals, containing inflammatory mediators and blood proteins, produced significantly less LA-to-SA conversion. This suggests stabilization of large surfactant particles against conversion to the less active smaller forms by substances present in lavage fluid (9). Similarly, addition of serum albumin to the bovine lung extract surfactant resulted in a significant reduction in formation of small surfactant aggregates (10).

Based on these later observations, the aim of the study was to prove the hypothesis that addition of fibrinogen preserves biophysical and physiological properties of natural modified surfactant subjected to long-term surface area cycling.

\section{RESULTS}

\section{In Vitro Studies}

The intention was to study the effect of cycling time as well surfactant concentration without and with fibrinogen on surface activity.

The effect of cycling time using a surfactant concentration of $10 \mathrm{mg} / \mathrm{ml}$ (Study 1). Surfactant was cycled at a phospholipid concentration of $10 \mathrm{mg} / \mathrm{ml}$ without or with fibrinogen $5 \mathrm{mg} / \mathrm{ml}$ at $37^{\circ} \mathrm{C}$ up to $23 \mathrm{~d}$ and in vitro properties were investigated 
by captive bubble surfactometer (CBS). Gradual reduction in surface activity of Curosurf cycled without fibrinogen, seen as an increase in minimum $(>5 \mathrm{mN} / \mathrm{m})$ and maximum surface tension (Figure1a,b), was present from day 18. Curosurf with fibrinogen reached high minimum surface tension by day 11 (Figure1a).

The effect of cycling time on surface activity and lipid peroxidation using a surfactant concentration of $80 \mathrm{mg} / \mathrm{ml}$ (Study 2). On the basis of the results in Study 1, day 6 and day 12 were chosen as time points of interest. The concentration of surfactant $(80 \mathrm{mg} / \mathrm{ml})$ was similar to that used for Curosurf in both animal experiments and clinical practice $(200 \mathrm{mg} / \mathrm{kg})$.

At day 6 Curosurf cycled without fibrinogen did not reach a minimum surface tension $<5 \mathrm{mN} / \mathrm{m}$ and inactivation was even more pronounced at day 12 (Figure 2a). Samples containing fibrinogen had low minimum surface tension comparable with noncycled Curosurf (Figure 2a). Similar trends were seen for maximum surface tension (Figure $2 \mathbf{b}$ ).

In samples of Curosurf cycled for 6 and $12 \mathrm{~d}$ lipid peroxidation was significantly higher in comparison with samples without cycling (day 0). Addition of fibrinogen to Curosurf prevented lipid peroxidation (Figure 3).

The effect of cycling time using two different surfactant concentrations (Study 3). In the previous experiments (Studies 1 and 2) we observed that the effect of fibrinogen on surface activity was dependent both on surfactant concentration and cycling time. Therefore, we decided to compare the two surfactant concentrations in the same experiment. Curosurf was cycled at $10 \mathrm{mg} / \mathrm{ml}$ without or with fibrinogen $(5 \mathrm{mg} / \mathrm{ml})$ and at $80 \mathrm{mg} / \mathrm{ml}$ without or with fibrinogen $(40 \mathrm{mg} / \mathrm{ml})$ at $37^{\circ} \mathrm{C}$ for $12 \mathrm{~d}$.

Minimum and maximum surface tension ( $\gamma \min$ and $\gamma \max )$ of Curosurf at $10 \mathrm{mg} / \mathrm{ml}$ were not substantially influenced by cycling for up to $12 \mathrm{~d}$ at $37^{\circ} \mathrm{C}$ irrespective of adding fibrinogen (Figure 4a,b). At phospholipid concentration of $80 \mathrm{mg} /$ $\mathrm{ml}, \gamma \min$ and $\gamma \mathrm{max}$ increased in samples of Curosurf without fibrinogen after 9 and $12 \mathrm{~d}$ of cycling but in samples containing fibrinogen the cycling time had no effect on surface tension (Figure 4a,b). The changes in surface activity are reflected also by values of area of compression needed to reach $\gamma \mathrm{min}$ of $5 \mathrm{mN} / \mathrm{m}$ (Figure 5).

\section{In Vivo Experiments}

The concept of animal experiments was based on the results of in vitro Study 2 and the shortest cycling time observed with reduced surface activity was used. Therefore, animals were treated at birth by noncycled Curosurf and Curosurf cycled at a concentration of $80 \mathrm{mg} / \mathrm{ml}$ with or without fibrinogen $(40 \mathrm{mg} / \mathrm{ml})$ for $6 \mathrm{~d}$.

There were no differences in body weight between the groups (Table 1). One animal treated with Curosurf had evidence of pneumothorax within the period of observation and was excluded from the final data analysis (Table 1).

At the beginning of ventilation-at pressures of 25 and $20 \mathrm{~cm}$ $\mathrm{H}_{2} \mathrm{O}$-animals treated with surfactant cycled with or without fibrinogen had significantly reduced mean tidal volumes in comparison with animals receiving noncycled Curosurf. After $30 \mathrm{~min}$ of ventilation, corresponding values for mean tidal volume in all surfactant-treated groups were similar $(\sim 21-22 \mathrm{ml} / \mathrm{kg}$ of body weight). Nontreated controls had statistically lower tidal volumes at all time points throughout the experiment (Figure 6).

Lung-gas volumes measured at the end of experiment were significantly higher in all treatment groups in comparison with controls (all $P<0.001$ ). Mean lung-gas volumes of animals treated with noncycled Curosurf or Curosurf cycled with fibrinogen at $37^{\circ} \mathrm{C}$ for $6 \mathrm{~d}$ were comparable $(\sim 18-19 \mathrm{ml} /$ $\mathrm{kg}$ body weight in both groups) and significantly higher than in rabbits treated with Curosurf cycled without fibrinogen (Figure 7).
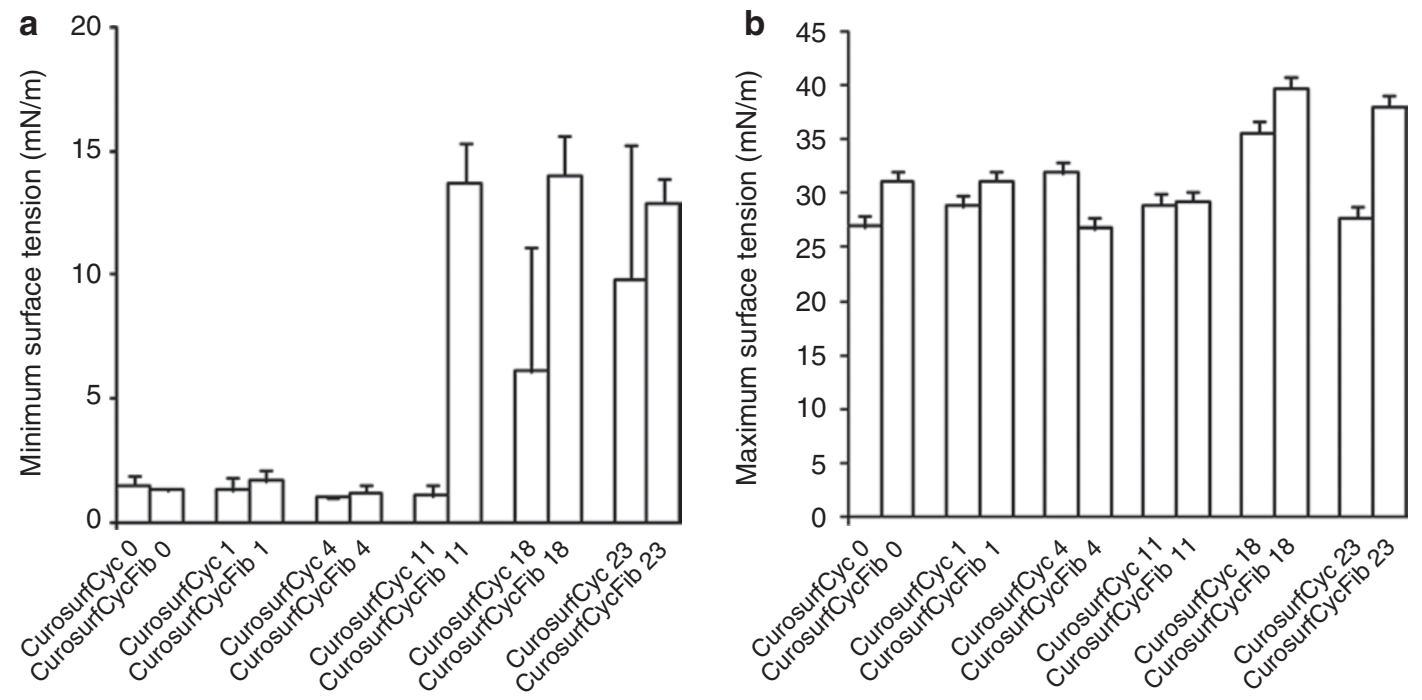

Figure 1. Dynamic surface properties of Curosurf with and without fibrinogen during long-term cycling. (a) Minimum and (b) maximum surface tension of Curosurf rotated at a concentration of $10 \mathrm{mg}$ phospholipids $/ \mathrm{ml}$ without (CurosurfCyc) and with fibrinogen ( $5 \mathrm{mg} / \mathrm{ml}$ ) (CurosurfCycFib) at $37^{\circ} \mathrm{C}$ up to $23 \mathrm{~d}$. Values are shown as mean $\pm \mathrm{SE}$ at minimum ( $\gamma \mathrm{min})$ and maximum ( $\gamma \mathrm{max})$ bubble size during fifth cycle in captive bubble surfactometer. Data are from three experiments. 

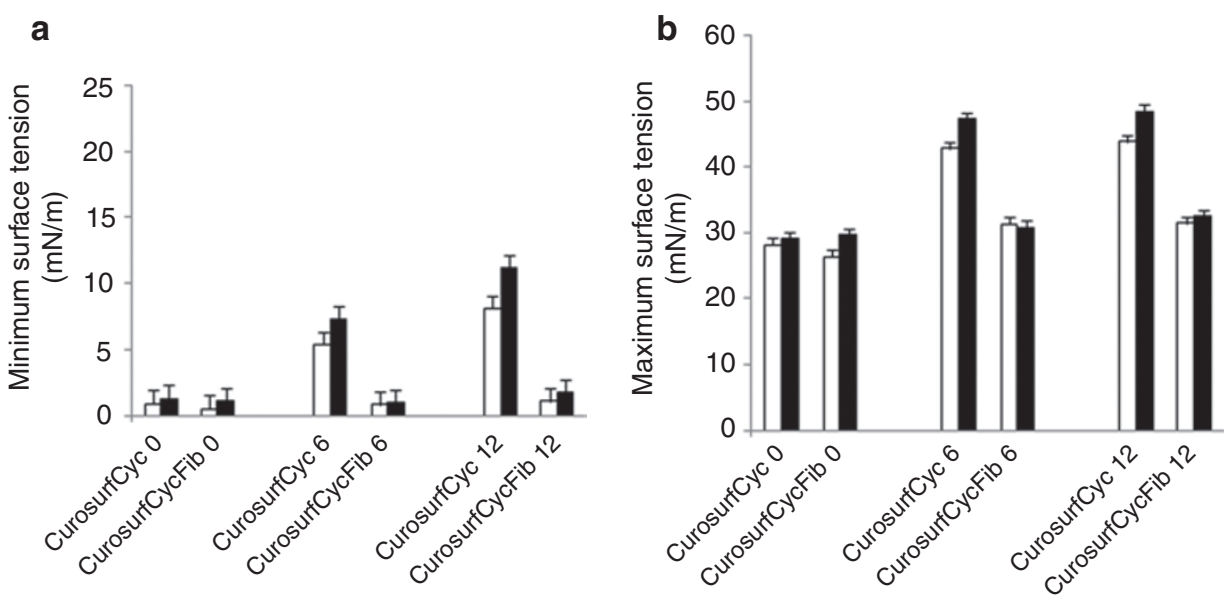

Figure 2. Dynamic surface properties of high-concentration Curosurf with and without fibrinogen cycled up to $12 \mathrm{~d}$. (a) Minimum and (b) maximum surface tension of Curosurf cycled at a concentration of $80 \mathrm{mg} / \mathrm{ml}$ without (CurosurfCyc) and with fibrinogen ( $40 \mathrm{mg} / \mathrm{ml})(\mathrm{CurosurfCycFib})$ at $37^{\circ} \mathrm{C}$ for 0 (control samples before cycling), 6 , and $12 \mathrm{~d}$. Values are shown as mean $\pm \mathrm{SE}$ at $\gamma \mathrm{min}$ and $\gamma$ max bubble size during first (white bars) and fifth (black bars) cycles in captive bubble surfactometer. Data are from five to seven experiments. Statistical analysis: CurosurfCyc 6 and CurosurfCyc 12 vs. all $P<0.001$ (for

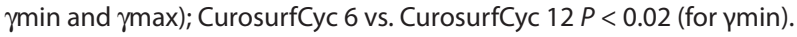

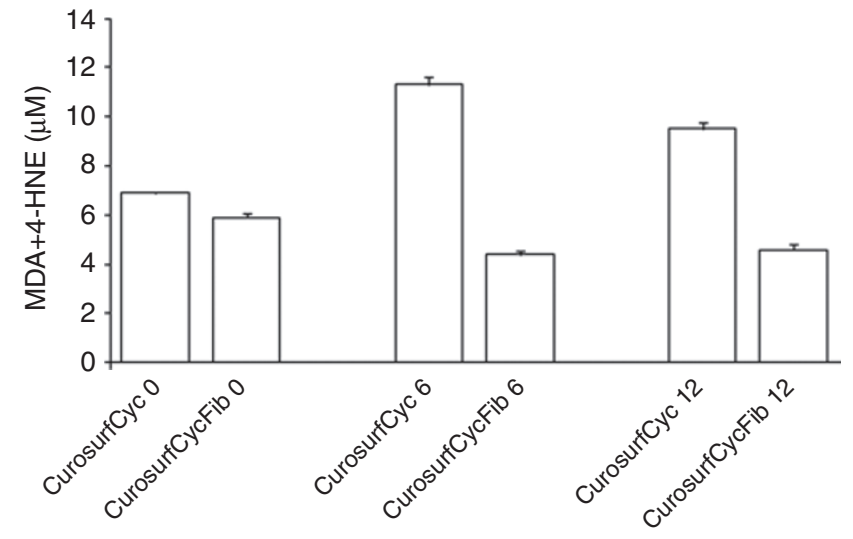

Figure 3. Lipid peroxidation expressed as accumulation of malondialdehyde and 4-hydroxyalkenals. Data are shown as mean \pm SE. Statistical analysis: CurosurfCyc 6 and CurosurfCyc 12 vs. all $P<0.001$; CurosurfCyc 6 vs. CurosurfCyc $12 P<0.001$.

Values on lung-gas volumes correspond to macroscopic appearance of the lungs (Figure 8) and are corroborated with data on alveolar volume density indicating the grade of alveolar expansion (Table 1). Nontreated controls had significantly lower values of alveolar volume density than all surfactanttreated groups. Percentage of alveolar volume density was significantly higher in groups treated with noncycled Curosurf or Curosurf cycled with fibrinogen than in the group treated with Curosurf cycled for $6 \mathrm{~d}$ without fibrinogen.

\section{DISCUSSION}

Fibrinogen is believed to be a strong inhibitor of pulmonary surfactant. In this study, we investigated the effects of fibrinogen on the natural modified surfactant Curosurf subjected to surface area cycling. This is an in vitro procedure for the conversion of large into small surfactant aggregates. It mimics repeated changes in surface area in the alveolus during the respiratory cycle. Methods of other authors $(8,10)$ of surface area cycling involve a temperature of $37-38^{\circ} \mathrm{C}$ and a cycling speed of $40 \mathrm{rpm}$ for $3 \mathrm{~h}$ at a low phospholipid concentration (0.03-0.25 mg phospholipids $/ \mathrm{ml})$. We used a lower cycling speed of $20 \mathrm{rpm}$, higher surfactant concentrations (10 and $80 \mathrm{mg}$ phospholipids $/ \mathrm{ml}$ ) and a much longer cycling period (up to $23 \mathrm{~d}$ ).

The purpose of the long-term cycling was to detect a moment when the changes in surface activity of surfactant cycled with or without fibrinogen become apparent. Cycling lasting $23 \mathrm{~d}$ was a part of a screening study that should reveal the dynamics of the changes. The half-life of ${ }^{13} \mathrm{C}$-labeled PC-palmitate measured in tracheal aspirates of preterm infants with respiratory distress syndrome (RDS) was $\sim 96 \mathrm{~h}$ and with another stabile isotopes it was up to $\sim 106 \mathrm{~h}$ (e.g., up to $5 \mathrm{~d}$ ) (11). Here is a clinical parallel why surfactant cycled for $6 \mathrm{~d}$ was intratracheally instilled in the prematurely born newborn rabbits.

The phospholipid concentrations used in our experiments are based on its calculated concentrations in the alveolar lining. In preterm infants with RDS, surfactant pool size in the alveolus is $\sim 2-10 \mathrm{mg} / \mathrm{kg}$ (12). For surfactant replacement therapy a majority of authors agree that the initial dose should be close to the estimated pool size of alveolar surfactant in a normal fullterm newborn baby, about $100 \mathrm{mg} / \mathrm{kg}$ (13). The phospholipid concentration used for our CBS study $(10 \mathrm{mg} / \mathrm{ml})$ corresponds to that in the alveoli and the concentration used for our in vivo studies $(80 \mathrm{mg} / \mathrm{ml}, 2.5 \mathrm{ml} / \mathrm{kg}$ ) mimics clinical situation, where a Curosurf dose of $200 \mathrm{mg} / \mathrm{kg}$ body weight is recommended by the supplier for neonatal RDS.

For evaluation in the CBS all samples were investigated at $10 \mathrm{mg} / \mathrm{ml}$ phospholipids with or without $5 \mathrm{mg} / \mathrm{ml}$ fibrinogen. The ratio between surfactant lipids and fibrinogen was always 2:1 (w/w) and it is comparable with others. Thus, Manalo et al. (7) tested surfactant diluted to $2.5 \mathrm{mg} / \mathrm{ml}$ mixed with 0.5 and $1 \mathrm{mg} / \mathrm{ml}$ fibrinogen (ratios 5:1 and 2.5:1).

Long-term surface area cycling of $10 \mathrm{mg} / \mathrm{ml}$ of Curosurf gradually increased minimum surface tension while cycling of 

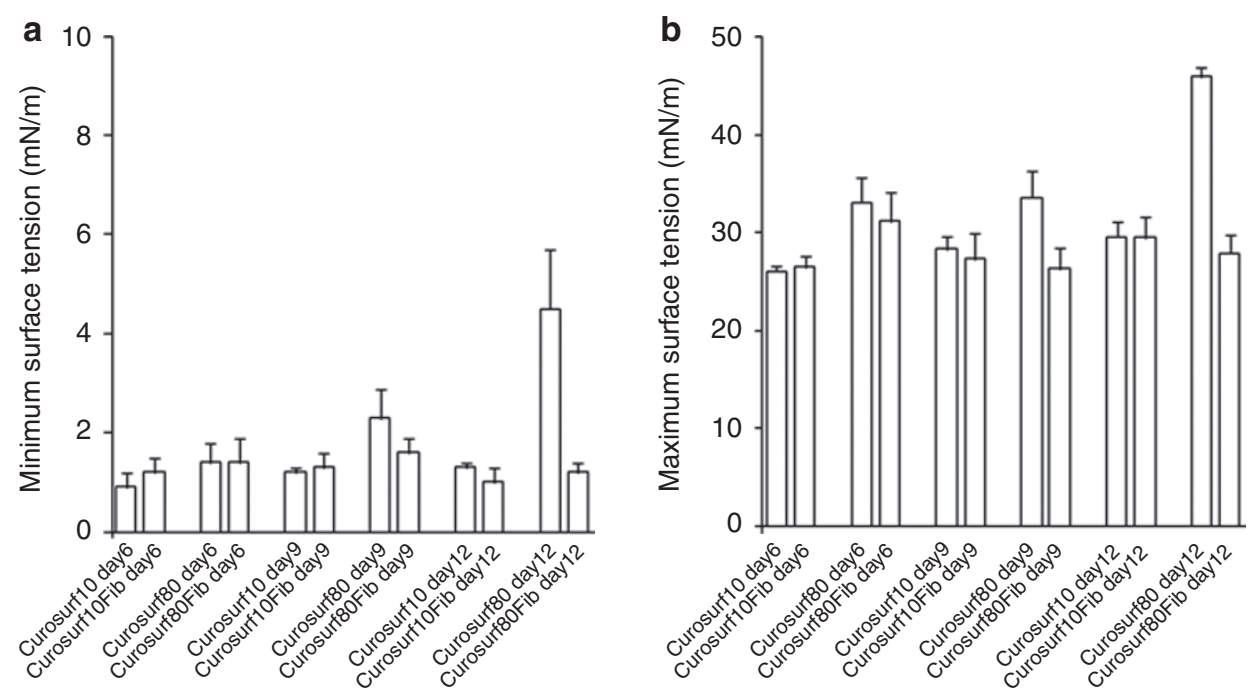

Figure 4. Dynamic surface properties of low and high concentrations of Curosurf with or without fibrinogen cycled up to $12 \mathrm{~d}$. (a) Minimum and (b) maximum surface tension of Curosurf rotated at a concentration of $10 \mathrm{mg} / \mathrm{ml}$ without (Curosurf10) and with fibrinogen ( $5 \mathrm{mg} / \mathrm{ml}$ ) (Curosurf10Fib), and at a concentration of $80 \mathrm{mg} / \mathrm{ml}$ without (Curosurf80) and with fibrinogen $\left(40 \mathrm{mg} / \mathrm{ml}\right.$ ) (Curosurf80Fib) at $37^{\circ} \mathrm{C}$ for 6,9 , and $12 \mathrm{~d}$. Values are shown as mean \pm

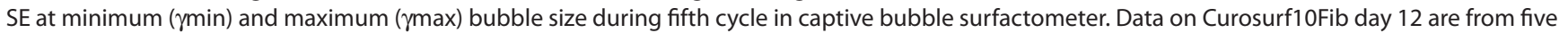
experiments; all other data are from three experiments.

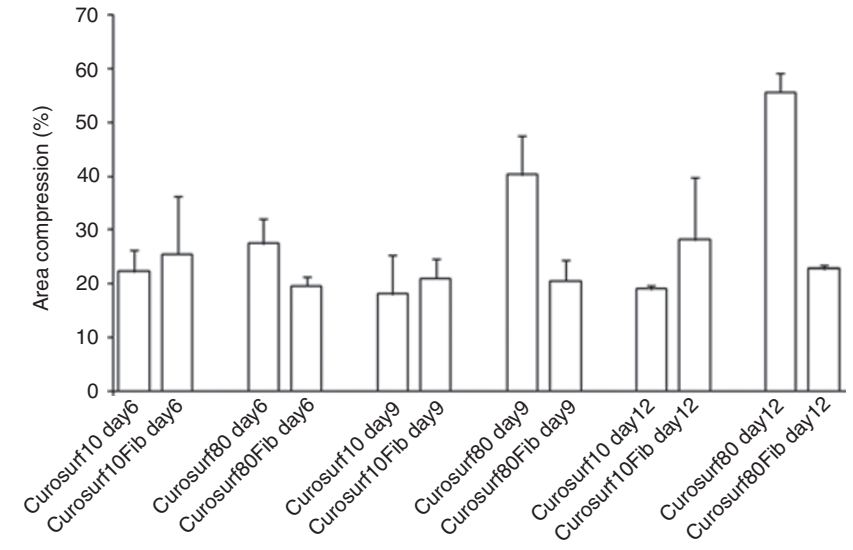

Figure 5. Area of compression needed to reach minimum surface tension ( $\gamma \mathrm{min}$ ) of $5 \mathrm{mN} / \mathrm{m}$ of Curosurf rotated at $10 \mathrm{mg} / \mathrm{ml}$ without (Curosurf10) and with fibrinogen $(5 \mathrm{mg} / \mathrm{ml}$ ) (Curosurf10Fib) and at a concentration of $80 \mathrm{mg} /$ $\mathrm{ml}$ without (Curosurf80) and with fibrinogen ( $40 \mathrm{mg} / \mathrm{ml}$ ) (Curosurf80Fib) at $37^{\circ} \mathrm{C}$ for 6,9 , and $12 \mathrm{~d}$ during fifth cycle in captive bubble surfactometer. Values are shown as mean \pm SE. Data on Curosurf10Fib day 12 are calculated from five experiments; all other data are from three experiments.

the surfactant/fibrinogen mixture increased surface tension at an earlier time point, confirming the generally accepted theory of inhibitory properties of fibrinogen. In Study 3 , the low concentration of Curosurf with fibrinogen added was still surface active after cycling for $12 \mathrm{~d}$ at $37^{\circ} \mathrm{C}$, indicating the variability in time for inactivation. On the other hand, surfactant cycled at high concentration $(80 \mathrm{mg} / \mathrm{ml})$ was inhibited by day $6(\gamma \mathrm{min}>$ $5 \mathrm{mN} / \mathrm{m}$ ), whereas fibrinogen added to surfactant clearly prevented its inactivation (Study 2). The results obtained in Study 3 for the high concentration were similar, but the inhibition was weaker and was observed at a later time point.

Results of the in vitro study were proven in premature newborn animals. Curosurf cycled at $80 \mathrm{mg} / \mathrm{ml}$ for $6 \mathrm{~d}$ with fibrinogen
Table 1. Body weight, numbers, incidence of pneumothorax, and alveolar volume density in different treatment groups of preterm newborn rabbits

\begin{tabular}{lcccc}
\hline Treatment & $\begin{array}{c}\text { Body } \\
\text { weight (g) }\end{array}$ & $n$ & $\begin{array}{c}\text { Incidence of } \\
\text { pneumothorax }\end{array}$ & $\begin{array}{c}\text { Alveolar volume } \\
\text { density (\%) }\end{array}$ \\
\hline $\begin{array}{l}\text { Curosurf cycled } \\
\text { without fibrinogen } \\
\text { (CurosurfCyc) }\end{array}$ & $31 \pm 1$ & 16 & 0 & $51.6 \pm 1.6^{*}$ \\
$\begin{array}{l}\text { Curosurf cycled } \\
\text { with fibrinogen } \\
\text { (CurosurfCycFib) }\end{array}$ & $31 \pm 2$ & 15 & 0 & $61.6 \pm 1.8$ \\
$\begin{array}{l}\text { Curosurf } \\
\text { noncycled }\end{array}$ & $30 \pm 2$ & 14 & 1 & $64.2 \pm 1.2$ \\
$\begin{array}{l}\text { (Curosurf) } \\
\begin{array}{l}\text { Nontreated } \\
\text { controls }\end{array}\end{array}$ & $30 \pm 1$ & 15 & 0 & $41.9 \pm 1.0^{*}$ \\
\hline
\end{tabular}

Values of body weight and alveolar volume density are means \pm SE.

$n$, number of animals included in final statistical analysis.

${ }^{*} P<0.001$ vs. all groups.

increased lung-gas volumes at end-expiration and significantly increased alveolar volume density in a similar manner as noncycled Curosurf. However, animals treated with Curosurf without and with fibrinogen had similar but lower tidal volume $\left(\mathrm{V}_{\mathrm{T}}\right)$ in the beginning of the experiment than animals treated with noncycled Curosurf. At the end of experiment at a peak inspiratory pressure of $25 \mathrm{~cm} \mathrm{H}_{2} \mathrm{O}$ all groups had similar $\mathrm{V}_{\mathrm{T}}$, which was significantly higher than in control animals. It may reflect a delay in opening of the lungs, probably due to a reduced adsorption rate of surfactant cycled regardless of the presence of fibrinogen (in vitro data not shown). Taken together, fibrinogen added to Curosurf subjected to surface area cycling improved alveolar stability at the end-expiration in the animal model of RDS.

In vivo testing of surfactant preparations in animal models has certain limitations. Optimally, treatment effect of surfactant 


\section{Articles $\mid$ Calkovska et al.}

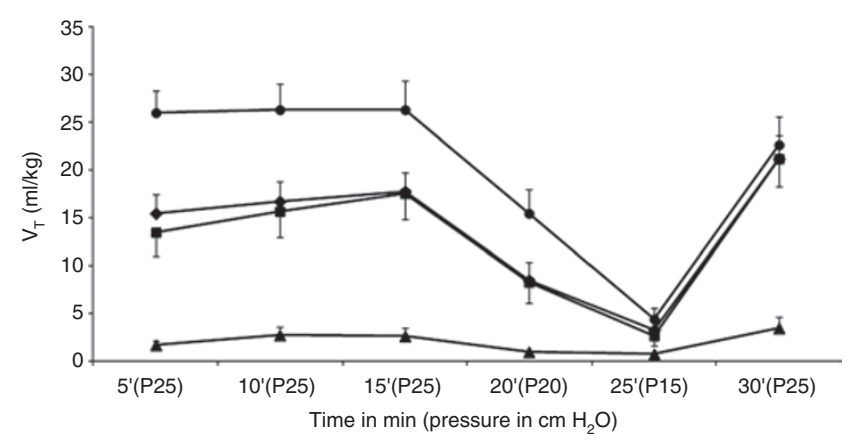

Figure 6. Tidal volume $\left(\mathrm{V}_{\mathrm{T}}\right)$ during $30 \mathrm{~min}$ of ventilation in preterm newborn rabbits treated with Curosurf (filled circle; $n=14$ ) and Curosurf cycled for $6 \mathrm{~d}$ without (CurosurfCyc) (filled square; $n=16$ ) or with fibrinogen (CurosurfCycFib) (filled diamond; $n=15$ ) at $37^{\circ} \mathrm{C}$, and for nontreated controls (filled triangle; $n=15$ ). Levels of statistical significance: At 5, 10, 15, and 20 min: for all treated groups vs. controls, $P<0.001-0.05$; for CurosurfCyc and CurosurfCycFib vs. Curosurf, $P<0.001-0.05$; at 25 min: for Curosurf vs. control, $P<0.05$; at 30 min: for all treated groups vs. control, $P<0.001$

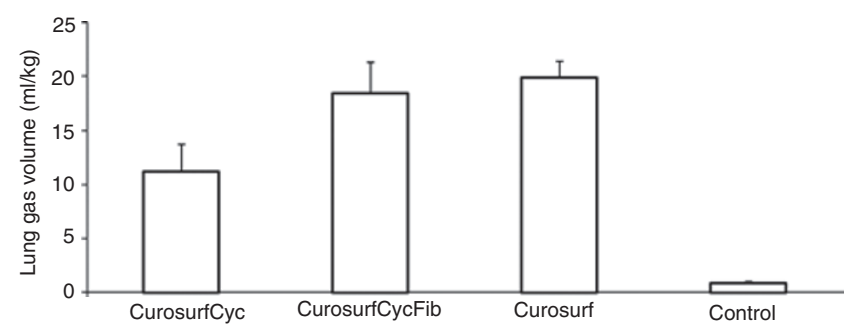

Figure 7. Lung-gas volumes measured at the end of the experiment in preterm newborn rabbits treated with Curosurf $(n=14)$ and Curosurf cycled for $6 \mathrm{~d}$ without (CurosurfCyc; $n=16$ ) or with fibrinogen (CurosurfCycFib; $n=15$ ) at $37^{\circ} \mathrm{C}$, and for nontreated controls ( $n=15$ ). For all surfactant-treated groups vs. control $P<0.001$; for CurosurfCyc vs. CurosurfCycFib $P<0.02$; and for CurosurfCyc vs. Curosurf $P<0.03$.

includes improvement in oxygenation and parameters of lung mechanics that should be determined for several hours to days after administration. Immature newborn animals are most relevant model of neonatal RDS. They do not have a sufficient amount of surfactant in their fetal lung fluid and are not able to establish functional residual capacity at birth (14). It is possible to test the effects of surfactant therapy on immature newborn rabbits for several hours, but long-term evaluation is limited because of their low body weight $(20-40 \mathrm{~g})$. For technical reasons it is too complicated to insert catheters for blood sampling or to give complex treatment that is required in clinical respiratory failure. Therefore, the model is most often used to evaluate the acute effects of surfactant replacement.

Among parameters of lung mechanics, compliance can be easily evaluated in this model. Lung-thorax compliance was derived from recordings of $\mathrm{V}_{\mathrm{T}}$ and peak inspiratory pressure and expressed as $\mathrm{ml} / \mathrm{kg} \cdot \mathrm{cm} \mathrm{H}_{2} \mathrm{O}$. As a protocol with standardized sequence of inspiratory pressures was used, the changes in lung compliance are identical with those in $\mathrm{V}_{\mathrm{T}}$ and were not shown.

In clinical settings babies are ventilated with positive endexpiratory pressure (PEEP), which prevents lung collapse and

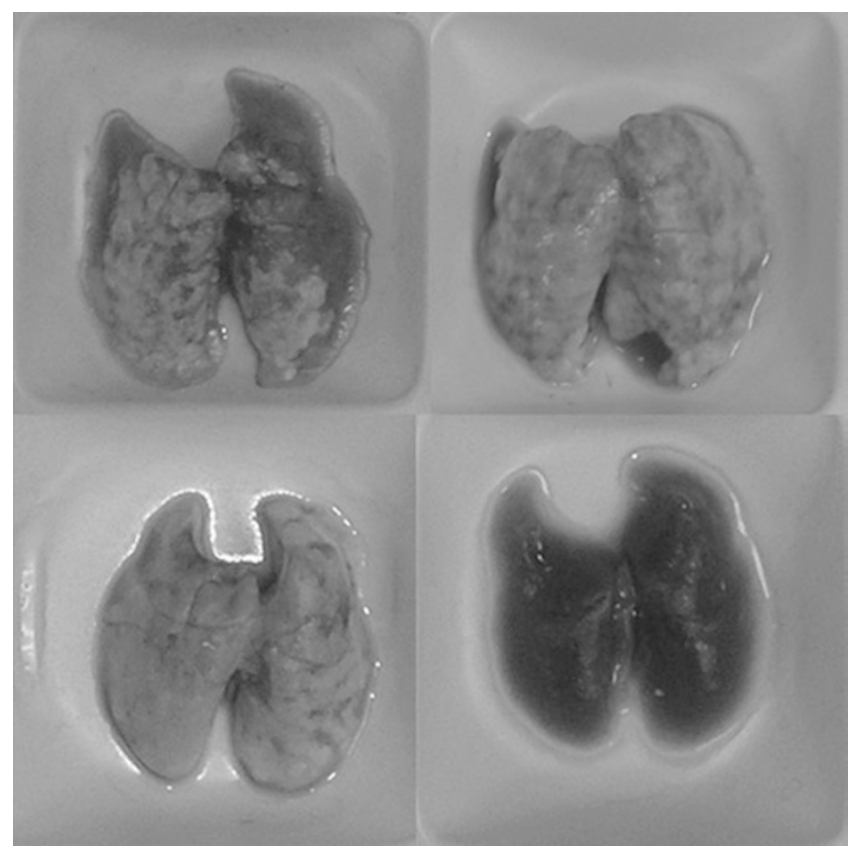

Figure 8. Representative macroscopic appearance of the lungs in preterm newborn rabbits after administration of Curosurf cycled for $6 \mathrm{~d}$ without (upper left) or with fibrinogen (upper right) at $37^{\circ} \mathrm{C}$, and Curosurf (lower left), and in nontreated control animals (lower right).

to some extent substitutes the function of missing or inactivated surfactant. In experimental settings ventilation of animals with PEEP may mask differences in tested surfactant preparations and therefore in some protocols administration of PEEP is avoided (15). It was our intention not to use PEEP because in our experiments PEEP would mask the differences in physiological effects by helping "low-quality surfactants" to be more efficient.

The results from Studies I and II suggested that surfactant inactivation by surface area cycling depends on phospholipid concentration. Study 3 proved concentration-dependent manner of surfactant inhibition by long-term area cycling that is probably due to enhanced LA-to-SA conversion. It is known that higher phospholipid concentrations in the cycling tube increase the amount of SA formed (10). Our samples with high phospholipid concentration have been more susceptible to changes in surface properties by surface area cycling at $37^{\circ} \mathrm{C}$, and fibrinogen added to surfactant at a ratio of $2: 1(\mathrm{w} / \mathrm{w})$ prevented the inactivation.

How can fibrinogen prevent surfactant inactivation during surface area cycling? In the similar model of surface area cycling (9), addition of supernatant from bronchoalveolar lavage fluid of injured animal lungs reduced the conversion from LAs to SAs. One explanation for this may be inhibition of the proteinase that is normally required for particle conversion. The authors suggested that any protein added in sufficient quantity might act as competitive inhibitor of an essential proteinase and block the cleavage of a physiological substrate. However, Curosurf, similar to other natural exogenous surfactants, is prepared by extraction with organic solvents and therefore it does not contain convertase. Therefore, the inactivation of surfactant subjected to surface area cycling should 
be a convertase-independent process because of adsorption of the surfactant at the changing interface. It seems possible that fibrinogen may prevent adsorption of surfactant to the wall of the tube and thus prevent LA-to-SA conversion (9).

Possible degradation of surfactant phospholipids or fibrinogen during long-lasting cycling also cannot be ruled out. On the other hand, fibrinogen degradation products have been proven to be more inhibitory to surfactant than fibrinogen itself (16). We can speculate that if fibrinogen would degrade it would have no protective effect during long-lasting cycling of surfactant.

The theory of inhibited aggregates conversion is further supported by the fact that addition of bovine serum albumin to the bovine lung extract surfactant subjected to surface area cycling resulted in a significant decrease in formation of SAs as compared with SA formation by bovine lung extract surfactant without albumin (17). Surface area cycling of both beractant and $\mathrm{KL}_{4}$ surfactant yielded light and heavy subtypes. However, in the presence of fibrinogen, cycling of beractant resulted in two separate heavy subtypes and cycling of $\mathrm{KL}_{4}$ surfactant in ultra-heavy subtypes that retained minimum surface tension comparable with that of native $\mathrm{KL}_{4}$ surfactant (7).

The positive effect of fibrinogen on surfactant subjected to surface area cycling could be partially mediated by reduction of surfactant lipid peroxidation. In this study the amounts of products of peroxidation were significantly reduced in samples with fibrinogen after 6 and $12 \mathrm{~d}$ of surface area cycling. This is in agreement with conclusions of Marzan et al. (6) that addition of serum proteins protects against, rather than promotes Fenton reaction-mediated chemical changes in surfactant lipids and proteins. Protection was greatest for fibrinogen. The ability of fibrinogen to protect against free-radical damage can be mediated by site-specific associations between negatively charged peptide side chains and the positively charged transition metal $\mathrm{Fe}^{2+}$, which is responsible for catalyzing the Fenton reaction (6). According to the authors, it is possible that serum proteins may act in vivo to prevent free radical-mediated damage to pulmonary surfactant.

The protective role of fibrinogen for peroxidation of phospholipids in vitro in our experiments can be explained by a mechanism based on the study of Malmsten (18). It was proven that adsorption of fibrinogen depends on the colloidal surface properties and that it is strongly influenced by hydrophobicity, surface charge, and the phospholipid head group. Fibrinogen, by interacting with lipid moieties, may form a "barrier" that prevents lipids from interaction (and damage) by surrounding oxygen. Although phosphatidylcholine gives a low adsorption of serum proteins, it may remain relatively fibrinogen-free and retain good in vitro and in vivo function.

\section{Conclusion}

The effect of fibrinogen on pulmonary surfactant cycled at $37^{\circ} \mathrm{C}$ depends both on surfactant concentration and cycling time. At the high phospholipid concentration used in clinical practice fibrinogen has a protective effect on biophysical and physiological properties of natural modified surfactant subjected to long-term surface area cycling. This effect is partially mediated by reduction in lipid peroxidation.

To our knowledge, this is the first study in which the protective effect of fibrinogen on pulmonary surfactant proved in vitro was corroborated by results from an animal model of respiratory distress syndrome. On the basis of the growing body of evidence from literature and data from this study, widely accepted opinion on the inhibitory properties of plasma proteins in regard to lung surfactant should be revised in the future.

\section{METHODS}

\section{In Vitro Studies}

Surfactant preparations. Poractant (Curosurf), $80 \mathrm{mg} / \mathrm{ml}$, is a modified natural porcine surfactant, which was obtained from Chiesi Farmaceutici, Parma, Italy. For in vitro studies it was diluted in $0.9 \%$ $\mathrm{NaCl}$ to a phospholipid concentration of $10 \mathrm{mg} / \mathrm{ml}$. Human plasma fibrinogen (Sigma, St Louis, MO) was added directly to surfactant in w/w ratio $2: 1$ and mixed.

Exposure to fibrinogen. In Study 1, $2 \mathrm{ml}$ of Curosurf at a concentration of $10 \mathrm{mg}$ phospholipids (PL)/ml without or with fibrinogen $5 \mathrm{mg} / \mathrm{ml}$ were added to a $10-\mathrm{ml}$ capped glass tube and were rotated at $20 \mathrm{rpm}$ and $37^{\circ} \mathrm{C}$ for $23 \mathrm{~d}$ to obtain a maximal change of the surface area. Aliquots were taken from the samples at time 0 , and at day 1,4 , 11,18 , and 23 of cycling. Surface activity of aliquots was measured by a CBS. On the basis of the results, day 6 and day 12 were chosen as time points of interest.

In Study 2, Curosurf was cycled under the same conditions as in Study $1\left(20 \mathrm{rpm}, 37^{\circ} \mathrm{C}\right)$ at $80 \mathrm{mg} \mathrm{PL} / \mathrm{ml}$ without or with fibrinogen $(40 \mathrm{mg} / \mathrm{ml})$ for 6 and $12 \mathrm{~d}$. Curosurf cycled at this concentration was further tested in animals treated with the clinically recommended dose of $200 \mathrm{mg} / \mathrm{kg}$. For evaluation of surface properties by CBS, Curosurf samples were diluted to $10 \mathrm{mg} / \mathrm{ml}$. In surfactant samples from Study 2 the degree of lipid peroxidation was determined (see below).

Study 3 was performed to investigate the effect of different phospholipid concentrations on Curosurf subjected to surface area cycling in the absence or presence of fibrinogen. Curosurf was cycled under the same conditions as in Studies I and II $\left(20 \mathrm{rpm}, 37^{\circ} \mathrm{C}\right)$ at a concentration of $10 \mathrm{mg} \mathrm{PL} / \mathrm{ml}$ without or with fibrinogen $(5 \mathrm{mg} / \mathrm{ml})$ and at a concentration of $80 \mathrm{mg} \mathrm{PL} / \mathrm{ml}$ without or with fibrinogen $(40 \mathrm{mg} / \mathrm{ml})$ up to $12 \mathrm{~d}$. Aliquots were taken from the samples at days 6,9 , and 12 . Evaluation of surface properties by CBS was done at concentration of $10 \mathrm{mg} \mathrm{PL} / \mathrm{ml}$.

Evaluation of surface activity by CBS. Surface activity of surfactant samples was measured by CBS; developed and built by Schürch and Bachofen (19) as previously described $(20,21)$. The test chamber was initially filled with $10 \%$ sucrose in saline. Two microliters of surfactant were injected into the sample chamber and allowed to migrate by buoyance to the agarose ceiling. An air bubble was then placed under the ceiling in contact with the surfactant preparation, and surface tension was measured from the time of bubble insertion. After $5 \mathrm{~min}$ of adsorption, the sample chamber was sealed, and the quasistatic cycling was initiated. The bubble was compressed stepwise until the surface tension $<5 \mathrm{mN} / \mathrm{m}$ was reached or to $50 \%$ area compression and thereafter expanded to the initial size. This maneuver was repeated five times. Minimum and maximum surface tension were estimated and for some samples the area of compression needed to reach $\gamma \mathrm{min}$ of $5 \mathrm{mN} / \mathrm{m}$ (area\%) was calculated. Three to seven samples were evaluated from each preparation.

Lipid peroxidation assessment. The degree of lipid peroxidation was determined by lipid peroxidation 586 colorimetric assay (OXIS International, Portland, OR). This test is based on the reaction of a chromogenic reagent (R1: $10.3 \mathrm{mM} \mathrm{N}$-methyl-2- phenylindole in acetonitrile) with secondary products-malondialdehyde and 4-hydroxyalkenals-at $45^{\circ} \mathrm{C}$ to yield a stable chromophore, with maximal absorbance at $586 \mathrm{~nm}(22)$. 
The experiments were done for Curosurf at a concentration of $80 \mathrm{mg} / \mathrm{ml}$ without or with fibrinogen at day 0 , and after 6 and $12 \mathrm{~d}$ of cycling at $37^{\circ} \mathrm{C}$ (Study 2) and repeated for two to five times. Before measurement, samples were diluted in $0.9 \%$ sodium chloride to phospholipid concentration of $10 \mathrm{mg} / \mathrm{ml}$.

A $200 \mu \mathrm{l}$ sample was transferred to an Eppendorf tube and 650 $\mu \mathrm{l}$ of $\mathrm{R} 1$, diluted with methanol $(3: 1 \mathrm{v} / \mathrm{v})$ was added. Then $150 \mu \mathrm{l}$ of R2 (15.4 mol/l methanesulfonic acid) was added and the content was mixed. The tubes were incubated at $45^{\circ} \mathrm{C}$ for $45 \mathrm{~min}$, centrifuged and the supernatant was transferred to a cuvette and the optical density was read at $586 \mathrm{~nm}$ by spectrophotometer (U-1100, Hitachi Medical, Tokyo, Japan). Calculations were done using a standard curve of known concentrations of malondialdehyde and 4-hydroxyalkenals.

\section{In Vivo Study}

General design of animal experiments. The experiments were performed on 61 preterm newborn rabbits (New Zealand White) from eight litters obtained by Caesarean section at a gestational age of $27 \mathrm{~d}$ (term, 31d). After delivery, the animals were anesthetized with an intraperitoneal injection of pentobarbital sodium (APL, Stockholm, Sweden; $6 \mathrm{mg} / \mathrm{ml}$; dose $0.1 \mathrm{ml}$ ), tracheotomized, paralyzed with intraperitoneal pancuronium bromide (Pavulon, Oragon Teknika, Boxtel, Holland; $0.2 \mathrm{mg} / \mathrm{ml}$; dose $0.1-0.15 \mathrm{ml}$ ) and kept in plethysmograph boxes at $37^{\circ} \mathrm{C}$. They were mechanically ventilated in parallel with a modified Servo-Ventilator (900B, Siemens-Elema, Solna, Sweden) with $100 \%$ oxygen, frequency of 40 breaths/min and an inspirationto-expiration ratio of $1: 1$. To open up the lungs, peak inspiratory pressure was first set to $35 \mathrm{~cm} \mathrm{H} \mathrm{H}_{2}$ for $1 \mathrm{~min}$. Then the pressure was lowered to $25 \mathrm{~cm} \mathrm{H}_{2} \mathrm{O}$ for $15 \mathrm{~min}$ and further on to $20 \mathrm{~cm} \mathrm{H}_{2} \mathrm{O}$ for $5 \mathrm{~min}$ and $15 \mathrm{~cm} \mathrm{H} \mathrm{H}_{2} \mathrm{O}$ for $5 \mathrm{~min}$. Finally, pressure was raised again to $25 \mathrm{~cm}$ $\mathrm{H}_{2} \mathrm{O}$ for $5 \mathrm{~min}(23,24)$, after which the lungs were ventilated for an additional $5 \mathrm{~min}$ with nitrogen. No positive end-expiratory pressure was applied.

The animals were randomized to receive at birth, via tracheal tube, $2.5 \mathrm{ml} / \mathrm{kg}$ of Curosurf, or Curosurf rotated at $37^{\circ} \mathrm{C}$ for $6 \mathrm{~d}$ with or without fibrinogen, all preparations in $80 \mathrm{mg} / \mathrm{ml}$. In control animals, no material was instilled into the airways.

At the end of the experiment, the tracheal tube was clamped at end-expiration and the trachea ligated. Animals were killed by intracranial injection of lidocaine (Xylocaine, Astra, Sodertalje, Sweden, $20 \mathrm{mg} / \mathrm{ml}$; dose $0.5 \mathrm{ml}$ ). The abdomen was opened and the diaphragm inspected for evidence of pneumothorax. The lungs were excised and weighed.

Lungfunction measurement. Peak inspiratory pressure was recorded with a pressure transducer (EMT34). Tidal volumes were recorded every 5 min with a Fleisch-tube and recording system PowerLab 4/20 (ADInstruments, Oxfordshire, UK). Lung-thorax compliance was derived from recordings of tidal volume and peak inspiratory pressure and expressed as $\mathrm{ml} / \mathrm{kg} . \mathrm{cm} \mathrm{H}_{2} \mathrm{O}$.

Determination of lung-gas volume. Lung-gas volume, expressed in $\mathrm{ml} / \mathrm{kg}$ of body weight, was determined by water displacement technique (25) using a difference between the total volume of the lung $\left(\mathrm{V}_{\text {lung }}\right)$ and the volume of the lung tissue $\left(\mathrm{V}_{\text {tissue }}\right)$, divided by the body weight. $\mathrm{V}_{\text {lung }}$ was derived by weighing the volume of water displaced by the submersed lung. The $\mathrm{V}_{\text {tissue }}$ was calculated by converting the wet weight of the lung into a volume by dividing the wet weight by the specific density of lung tissue. Lung weight and $V_{\text {lung }}$ were determined in separate series of experiments and the method is described elsewhere $(20,26)$.

Morphometric examination of lungs. The lungs were fixed by immersion in $4 \%$ formalin and embedded in paraffin. Transverse sections from all lobes were stained with hematoxylin and eosin. Volume density of alveolar spaces was determined by computerized image analysis $(27,28)$ using total parenchyma as reference volume. The morphometric examination was blinded, i.e., the examiner was unaware of the experimental conditions of individual animals.

Ethical approval. The animal study was carried out in accordance with EU Directive 2010/63/EU for animal research and was approved by Local Ethical Committee for Animal Research, Stockholms Norra Djurförsöksetiska Nämnd No. N275/09.
Statistics. Data are expressed as mean \pm SE, or as median (range). The statistical program STATISTICA version 9.1 (StatSoft, Tulsa, OK) was used for data analysis. Between-group differences were examined by ANOVA followed by Neuman-Keuls' post hoc test. Data not normally distributed were analyzed by Kruskal-Wallis test. A $P$ value $\leq 0.05$ was regarded as statistically significant.

\section{STATEMENT OF FINANCIAL SUPPORT}

The study was supported by the Swedish Heart-Lung Foundation and Chiesi Farmaceutici.

\section{REFERENCES}

1. Seeger W, Stöhr G, Wolf HR, Neuhof H. Alteration of surfactant function due to protein leakage: special interaction with fibrin monomer. J Appl Physiol 1985;58:326-38.

2. Fuchimukai T, Fujiwara T, Takahashi A, Enhorning G. Artificial pulmonary surfactant inhibited by proteins. J Appl Physiol 1987;62:429-37.

3. Cockshutt AM, Weitz J, Possmayer F. Pulmonary surfactant-associated protein A enhances the surface activity of lipid extract surfactant and reverses inhibition by blood proteins in vitro. Biochemistry 1990;29:8424-9.

4. Holm BA, Enhorning G, Notter RH. A biophysical mechanism by which plasma proteins inhibit lung surfactant activity. Chem Phys Lipids 1988;49:49-55.

5. Gunasekara L, Schoel WM, Schürch S, Amrein MW. A comparative study of mechanisms of surfactant inhibition. Biochim Biophys Acta 2008;1778:433-44.

6. Marzan Y, Mora R, Butler A, Butler M, Ingenito EP. Effects of simultaneous exposure of surfactant to serum proteins and free radicals. Exp Lung Res 2002;28:99-121.

7. Manalo E, Merritt TA, Amirkhanian JD, Kheiter A. Characterization of surfactant subtypes of beractant and a synthetic peptide containing surfactant KL4 following surface area cycling and addition of fibrinogen. Lung 1997;175:225-33.

8. Gross NJ, Narine KR. Surfactant subtypes of mice: metabolic relationships and conversion in vitro. J Appl Physiol 1989;67:414-21.

9. Hall SB, Hyde RW, Kahn MC. Stabilization of lung surfactant particles against conversion by a cycling interface. Am J Physiol 1997;272(2 Pt 1):L335-43.

10. Veldhuizen RA, Yao LJ, Lewis JF. An examination of the different variables affecting surfactant aggregate conversion in vitro. Exp Lung Res 1999;25:127-41.

11. Zimmermann LJ, Janssen DJ, Tibboel D, Hamvas A, Carnielli VP. Surfactant metabolism in the neonate. Biol Neonate 2005;87:296-307.

12. Jobe A. Metabolism of endogenous surfactant and exogenous surfactants for replacement therapy. Semin Perinatol 1988;12:231-44.

13. Jobe AH, Ikegami M. Biology of surfactant. Clin Perinatol 2001;28:655-69, vii-viii.

14. Robertson B, Schurch S. Assessment of surfactant function. In: Uhlig S, Taylor AE, eds. Methods in Pulmonary Research. Basel-Boston-Berlin: Birkhäuser Verlag; 1998. pp. 349-83.

15. Curstedt $T$, Johansson J. Different effects of surfactant proteins B and C - implications for development of synthetic surfactants. Neonatology 2010;97:367-72.

16. Seeger W, Grube C, Günther A. Proteolytic cleavage of fibrinogen: amplification of its surfactant inhibitory capacity. Am J Respir Cell Mol Biol 1993;9:239-47.

17. Veldhuizen RA, Hearn SA, Lewis JF, Possmayer F. Surface-area cycling of different surfactant preparations: SP-A and SP-B are essential for largeaggregate integrity. Biochem J 1994;300 (Pt 2):519-24.

18. Malmsten M. Protein adsorption at phospholipid surfaces. J Colloid Interface Sci 1995;172:106-15.

19. Schürch S, Bachofen H. Biophysical aspects in the design of a therapeutic surfactant. In: Robertson B, Taeusch HWE, eds. Surfactant Therapy for Lung Disease. New York: Marcel Dekker, 1995:3-32.

20. Almlén A, Stichtenoth G, Linderholm B, et al. Surfactant proteins $\mathrm{B}$ and $\mathrm{C}$ are both necessary for alveolar stability at end expiration in premature rabbits with respiratory distress syndrome. J Appl Physiol 2008;104:1101-8. 
21. Stichtenoth G, Linderholm B, Björkman MH, Walter G, Curstedt T, Herting E. Prophylactic intratracheal polymyxin B/surfactant prevents bacterial growth in neonatal Escherichia coli pneumonia of rabbits. Pediatr Res 2010;67:369-74.

22. Bouhafs RK, Samuelson A, Jarstrand C. Lipid peroxidation of lung surfactant due to reactive oxygen species released from phagocytes stimulated by bacteria from children with cystic fibrosis. Free Radic Res 2003;37:909-17.

23. Berggren P, Curstedt T, Grossman G, Nilsson R, Robertson B. Physiological activity of pulmonary surfactant with low protein content: effect of enrichment with synthetic phospholipids. Exp Lung Res 1985;8:29-51.

24. Curstedt T, Jörnvall H, Robertson B, Bergman T, Berggren P. Two hydrophobic low-molecular-mass protein fractions of pulmonary surfactant. Characterization and biophysical activity. Eur J Biochem 1987; 168:255-62.

25. Sherle W. A simple method for volumetry of organs in quantitative stereology. Mikroskopie 1970; 26:57-60.

26. Johansson J, Some M, Linderholm BM, Almlén A, Curstedt T, Robertson B. A synthetic surfactant based on a poly-Leu SP-C analog and phospholipids: effects on tidal volumes and lung gas volumes in ventilated immature newborn rabbits. J Appl Physiol 2003;95:2055-63.

27. Rigaut JP, Robertson B. Quantitative evaluation of neonatal lung expansion with automated image analysis. Pediatr Pathol 1986;6:11-24.

28. Berggren P, Rigaut JP, Curstedt T, Robertson B. Computerized image analysis of lung expansion patterns in surfactant treated immature newborn rabbits. Respir Physiol 1999;115:45-53. 